Article

\title{
Bearing Fault Analysis of BLDC Motor for Electric Scooter Application
}

\author{
Karolina Kudelina ${ }^{1, *}$, Bilal Asad ${ }^{1}\left(\mathbb{D}\right.$, Toomas Vaimann ${ }^{1,2}$, Anouar Belahcen ${ }^{1,3}{ }^{\mathbb{D}}$, \\ Anton Rassõlkin ${ }^{1,2}$ (D) Ants Kallaste ${ }^{1}$ (D) and Dmitry V. Lukichev ${ }^{2}$ (D) \\ 1 Department of Electrical Power Engineering and Mechatronics, Tallinn University of Technology, \\ 19086 Tallinn, Estonia; bilal.asad@taltech.ee (B.A.); toomas.vaimann@taltech.ee (T.V.); \\ Anouar.Belahcen@aalto.fi (A.B.); anton.rassolkin@taltech.ee (A.R.); ants.kallaste@taltech.ee (A.K.) \\ 2 Faculty of Control Systems and Robotics, ITMO University, 197101 Saint Petersburg, Russia; \\ lukichev@itmo.ru \\ 3 Department of Electrical Engineering and Automation, Aalto University, FI-00076 Espoo, Finland \\ * Correspondence: karolina.kudelina@taltech.ee
}

Received: 3 September 2020; Accepted: 15 September 2020; Published: 3 October 2020

check for updates

\begin{abstract}
In this paper, the bearing faults analysis of the brushless DC motor is presented. The research method is based on the analysis of the vibration signal of healthy as well as faulty bearings by the identification of specific frequencies on the vibration spectrum. For the experiment, the most common faults were inflicted on the bearings. As the used motor is intended for electric scooter applications, seven different damages were chosen, which are highly likely to occur during the scooter operation. The main bearing faults and the possibility of fault monitoring are addressed. The vibration data are gathered by the acceleration sensors placed on the motor at different locations and the spectrum analysis is performed using the fast Fourier transform. The variation in the amplitude of the frequency harmonics particularly the fundamental component is presented as a fault indicator.
\end{abstract}

Keywords: ball bearings; DC motors; brushless machine; fault diagnosis; vibration measurement

\section{Introduction}

In recent years, brushless DC (BLDC) motors have gained wide attention in the electrical machine industry. The main feature of BLDC motors lies in their construction. The absence of brushes makes the machines more reliable and efficient. Moreover, brushless construction reduces the overall dimensions and weight of the motor. Because of these benefits, BLDC motors have attracted the interest of many researchers.

Brushless construction makes BLDC motors valuable in different industries. Because of the fact that BLDC motors are controlled electronically, these motors play an important role in applications, where sparks can be a critical factor [1]. In addition, brushless machines have gained a wide attention in different domestic applications [2-4]. Besides, BLDC motors have the potential of contributing to renewable energy [5-7].

During the last years, BLDC motors have contributed to the development of environmentally friendly and innovative electric vehicles. Many studies have been done with the purpose of comparing different motor types and their suitability for automotive applications [8]. BLDC motors are more preferable for electric vehicle applications because of the wide speed and power ranges [9-11]. Another noticeable trend in the automotive industry is the integration of BLDC motors into electric scooter applications, where the main requirements from the motor are high power density and starting torque [12]. BLDC motors meet those requirements for most of the special applications quite easily as compared to the other type of machines. 
As discussed, BLDC motors have found usage in a variety of applications; therefore, unexpected failures of such machines are undesirable and are to be avoided. Studies related to the faults of BLDC motors focus generally on the stator windings or rotor related faults, also problems related to Hall-effect sensors are studied in detail [13-15]. However, there are only a few researches dedicated to the study of bearing-related faults [16]. Nonetheless, taking into account the growth in usage of BLDC motors, the sudden failure of such a basic and important component as a bearing can have significant economic and dangerous consequences. Therefore, condition monitoring and ensuring the reliability of the bearing is extremely important.

The fields of condition monitoring and signal processing are directly related to each other. The selection of the appropriate signal along with the suitable signal processing technique is the most important step for predictive maintenance $[17,18]$. Almost all advanced signal processing algorithms rely on the basic signal processing techniques such as Fourier transform, short time Fourier transform, and wavelet transform, etc. The fundamental objective of these techniques is to detect the fault-based frequency components from the signal under investigation. Several research articles related with these techniques can be found in the literature. In $[19,20]$ fast Fourier transform (FFT) was used to investigate the stator current of squirrel cage induction motor for the segregation of supply, spatial, and fault-based harmonics. In [21] FFT was used along with a band stop filter to improve the legibility of current spectrum for fault diagnostics of induction motor. In [22] FFT was used for the validation of the simulation results with that obtained from the practical setup. In [23], evaluation based on wavelet transforms new processing method to detect stator related faults in the induction motors was presented. In [24], authors use wavelet transform for bearing fault diagnostics.

In general, the vibration analysis has been widely used for electrical machines fault analysis in the past decades. This technique offers more precise fault analysis and results compared to other techniques, especially, in the case of BLDC motors. In this work, vibration signal analysis was used for the study of the bearing faults of BLDC machine. The vibration analysis has several advantages over traditional diagnostic techniques, such as motor current signature analysis (MCSA), leakage flux analysis, etc. The MCSA-based fault definition frequencies are well-defined in the case of high power induction and synchronous machines. However, in the case of special purpose machines, like BLDC, the impact of drives and complex structure makes conventional MCSA techniques hazier. In contrary, the vibration signal does not need any specific definition equations. The diagnostic algorithm can be made reliable and the fault can be detected only by comparing the faulty vibration signal with the healthy one. The amplitude of the fundamental vibration frequency component can be used as a threshold and a reliable indicator of fault rather than the detection of certain harmonics from a wide range of frequencies.

The main core of this paper is related to the bearing faults of BLDC motors. The aim is to present a study where typical bearing damages are implemented on healthy bearings, in order to explore the impact of these faults on machine performance. This paper is arranged as follows. Section 2 presents possible bearing faults of BLDC motors. In Section 3, fault diagnostic possibilities are described. In Section 4, experimental setup and research methods are pointed out. Section 5 shows the results analysis and discussion of performed research, and finally, Section 6 presents the conclusion.

\section{Bearing Faults}

Bearing is a basic element of an electrical machine. The production of bearings is carried out under stringent requirements for the quality. However, the actual lifespan of the bearing can be lower than it was intended to be. This can occur because of many reasons, such as unexpected overload, insufficient lubrication or improper lubricant, improper bearing installation, etc. Because of the fact that the operating conditions of electrical machines can be different, the bearing can be affected by many fault types. The reasons for bearing failures can be different environmental or manufacturing factors, such as [25]: 
(1) Bad lubrication;

(2) Wrong emplacement;

(3) Contamination;

(4) Shaft currents.

By monitoring the operation of bearings, measuring temperature, noise, vibration, and periodically analyzing the quality of the lubricant, the risk of bearing damage can be significantly reduced.

\subsection{Material Fatigue}

This phenomenon is usually caused by cyclic and continuous loads, which crack the surface of the bearing. When cyclic stresses are applied to a material, failure of the material occurs at stresses much below the ultimate tensile strength of the material, because of the accumulation of damage [26]. If fatigue cracking progressively expands to a larger surface, the bearing eventually becomes unsuitable for further operation.

The durability of a bearing is counted in the number of revolutions that the bearing makes before the first signs of fatigue failure become noticeable on raceways and rolling bodies. Progressive stages of material fatigue on the bearing surface are shown in Figure 1.

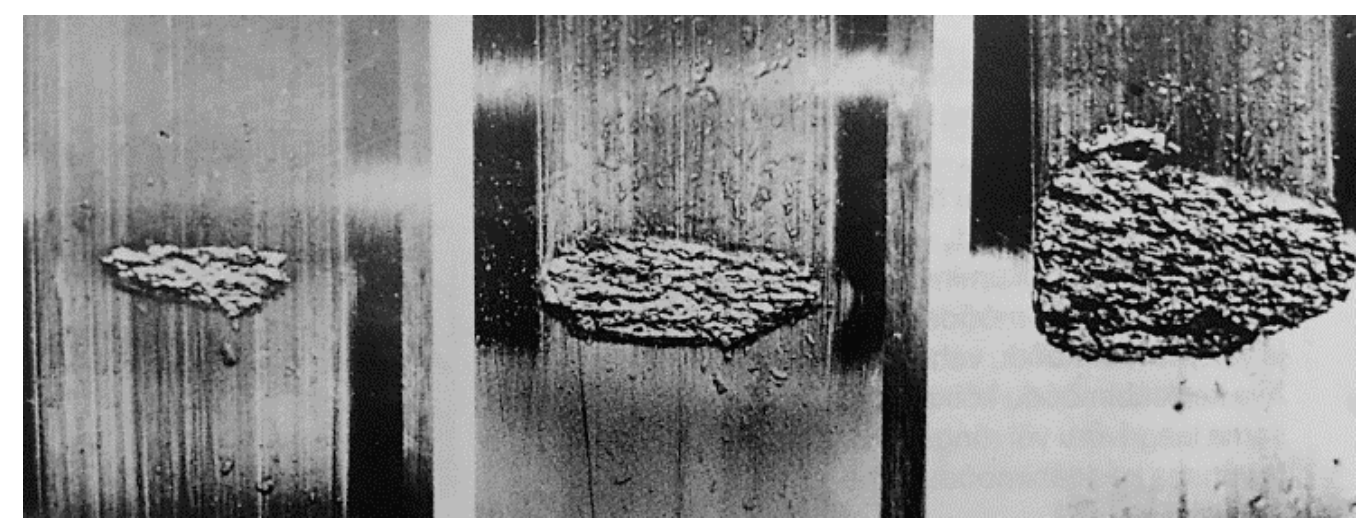

Figure 1. Progressive stages of material fatigue on the bearing surface [27].

The time when the first signs of material fatigue appear on the bearing surface depends on the rotational speed of the bearing and the magnitude of the load. In the initial stage of fault development, some microcracks remain on the subsurface. By further damage development, the surface of the bearing begins to exfoliate and crack on a larger surface. As a result, the surface of the bearing becomes rough. At this stage, the first symptoms are additional noise and vibration. Moreover, the operating temperature of the bearing increases. Constant overload, poorly treated, and contaminated surfaces inevitably lead to fatigue phenomena. This can be avoided or significantly slowed down if the bearing is clean (not contaminated) and well lubricated.

\subsection{Improper Lubrication}

One of the most important operating conditions for a bearing, which determines the durability of a bearing, is its proper lubrication. Correctly selected lubricant forms a thin oil coating, which softens the impact of the rolling bodies against the bearing cage and rings. Additionally, the lubricant protects the bearing from corrosion and wear.

The fact of improper lubrication can occur in the case of either insufficiently or excessively greased bearing. Insufficient lubrication, which can occur because of low viscosity of the lubricant or its small amount, causes friction and crack progression. Over-greasing results in undesirable shaft slipping and leads to structural damage of the bearing. 
Additionally, improper selection of the lubricant can have a negative impact on bearing operation. Grease lubrication as well as different oil-based lubricants (oil-mist, air-oil, or jet lubricants) are used in bearings. Each lubrication method has its unique advantages. The main criterion for selecting between grease and oil-based lubrication is to minimize the total life-cycle cost of the motor, including such parameters as cost of service, repair, maintenance of the motor, and the number of years the motor remains in service $[28,29]$. The life-cycle analysis implies important procedures in order to reduce impact of electric machines on the environment [30]. To meet this requirement, the lubricant method should be selected respectively to the operating conditions of the bearing. The choice of lubricant depends on the operating conditions of the bearing, in particular the temperature range, speed, and operating environment. Lubrication of bearings is mainly carried out using greases. The main advantage of grease over oils is that it operates in friction places for a longer time and thus reduces spending. However, oil-based lubricants are also widely used. A significant advantage of oils over greases is improved heat dissipation. However, compared to greases, the disadvantages of oils are high price and risk of leakage.

\subsection{Wrong Emplacement}

The defects in the bearings may also come up due to improper design of the bearing or improper manufacturing or mounting, misalignment of bearing races, the unequal diameter of rolling elements [31]. Before mounting, the bearing should be checked for manufacturing faults: compliance with the appearance, ease of rotation, and clearances to the requirements of technical documentation. Visually, bearings of open-type must be checked for nicks, traces of contamination, corrosion. For sealed-type bearings, the gaskets should be checked to detect possible damages.

Before the installation, the mounting surfaces of the shells and shafts have to be checked. The surfaces of shafts and shells mating with bearings must be thoroughly washed, wiped, dried, and greased with a thin layer of lubricant. Additionally, the alignment of the shaft must be controlled. It is necessary to check the deviation from the alignment of all landing surfaces located on the same axis for compliance with the standards specified in the technical documentation.

The application of mounting forces to the separator or hit directly on the ring is inappropriate. It is allowed to apply light blows to the ring only through a sleeve of non-hardened structural steel. The most appropriate are the mounting methods in which simultaneous and uniform pressure is applied around the entire circumference of the mounted ring.

In Figure 2a, a chip on a large rib of the inner ring of a tapered bearing is shown. This occurs when an incorrect axial or heavy striking load is applied to the bearing. In addition, it can occur if inappropriate force was applied to the rib during installation or dismantlement of the bearing. Cracks, as shown in Figure 2b, appear as a result of the application of heavy striking load or excessive tightness. This phenomenon is observed in those cases when the outer ring is weakly established on the shaft, and slip occurs.

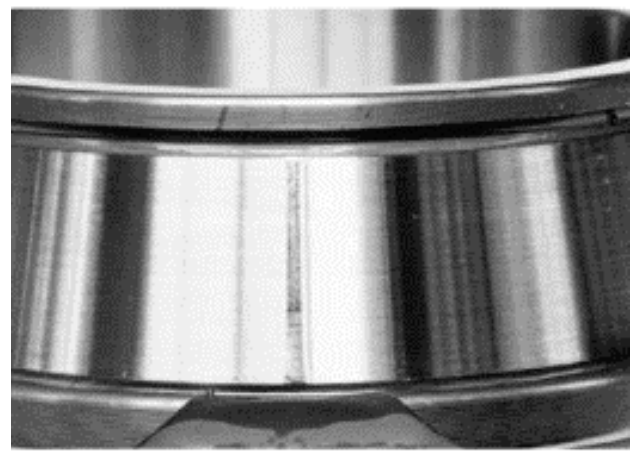

(a)

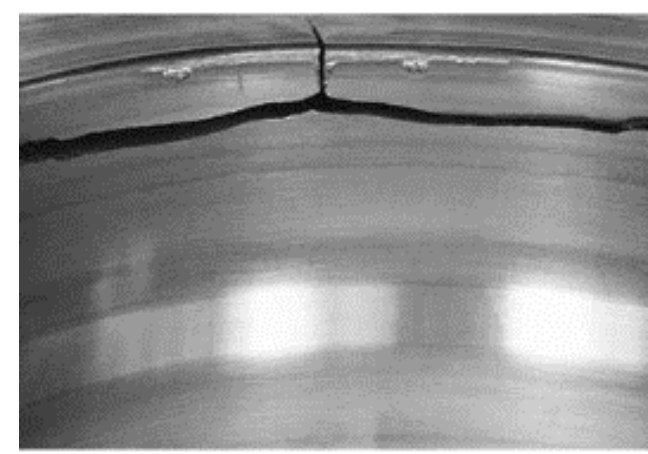

(b)

Figure 2. Chips (a) and cracks (b) due to the wrong emplacement of the bearing [32]. 


\subsection{Contamination}

Corrosion is a process between material and environment, which results in material dissolution. Corrosion can be caused by moisture that enters the bearing from the atmosphere. Humid air enters the bearing and tears the lubricating coating at the contact points of surfaces and raceways. In addition, the grease can become contaminated when water or other chemically active substances pollute the lubricant. As the lubricant properties are deteriorated, bearing corrosion is caused. To prevent this failure, the corrosion-resistant greases can be used. The possible impact of the environment on the bearing is shown in Figure 3.

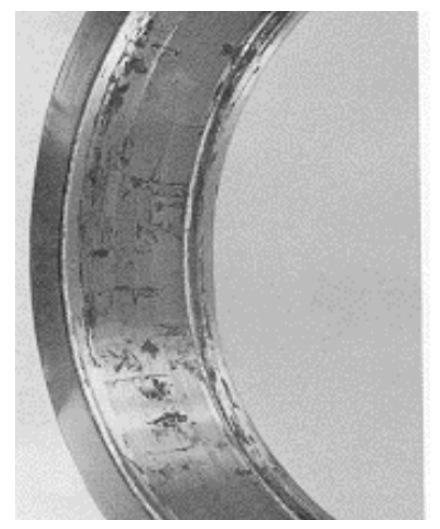

(a)

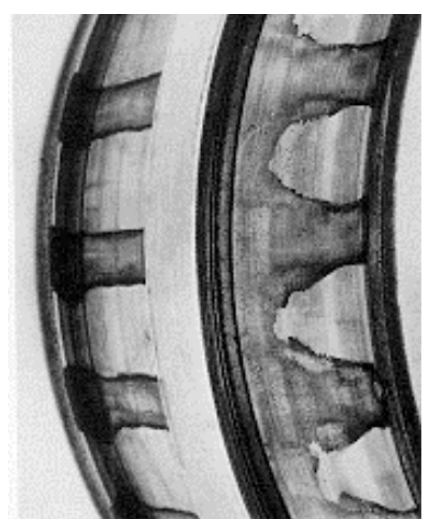

(b)

Figure 3. Traces of corrosion on the bearing surface: (a) Traces of corrosion on the outer ring of the bearing; (b) traces of corrosion due to the water impact on the inner ring of the bearing [33].

Bearings can be polluted by sand, dust, or other abrasive particles, which in turn interferes with bearing operation and leads to scratches, cracks, or other structural damage [34]. Mainly, it can occur in hand with wrong bearing gasket selection. This can cause an entering of various particles (dust or dirt) into the bearing. Foreign particles, such as metal shavings that penetrate the bearing, produce dents when the rolling body rolls the shaving into the raceway. In order to prevent this, the right gasket should be selected. Also, it is important to keep clean during assembly and not to use contaminated lubricants.

\subsection{Shaft Currents}

Bearings can be affected by shaft currents. This fault occurs when electric current passes the bearing from one ring to another through the rolling elements. The size of the damage depends on the level of the current, exposure time, load, rotational speed, lubricant selection. More frequently, the damages related to shaft current can be indicated by increased noise and vibration. In addition, shaft currents cause the heating of the bearing material. Sometimes it can lead to the fusion of the material. As a result, a variety of colored areas are formed on the surface of the bearings, as well as the rolling elements.

This fault is clearly detectable on the bearing surface. Shaft current damages usually appear in the areas of the bearing, which were loaded the most. The reason for this is that the lubricant coating in the area is the thinnest, which contributes to the damage development. The appearance of damaged surfaces is related to three major types of current faults in the bearing: "fluting," "frosting," and "pitting." The visual appearance of these damages is shown in Figure 4.

The first shaft current fault, called fluting, occurs in the combination of low voltage and constant rotational speed. Fluting is characterized by multiple lines across the inner and outer rings, as shown in Figure $4 a$. Another shaft current fault, shown in Figure $4 b$, is called frosting. This damage occurs when the motor runs at varying speeds. Pitting is caused by the low rotational speed in combination 
with the high voltage source. It is mostly related to single crater damage and typically seen in DC applications such as railway traction motors [35]. The size of the crater is small, as shown in Figure 4c but visible to the naked eye. Practically, yet another current fault can be detected, which is called dull-finish. This damage resembles pitting, but the craters on the bearing surface are much smaller. The appearance of these craters can only be detected under a microscope using very high magnification. To limit the negative impact of shaft currents, electric current should not be passed through the bearing. In this case, bearings with electrical insulation can be used. Additionally, during electrical welding operations, the motor shaft should be grounded to prevent the passage of electric current.

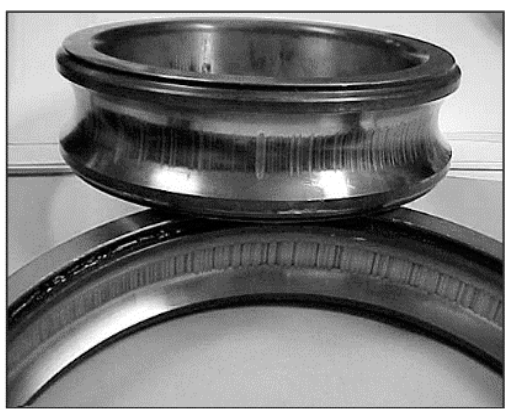

(a)

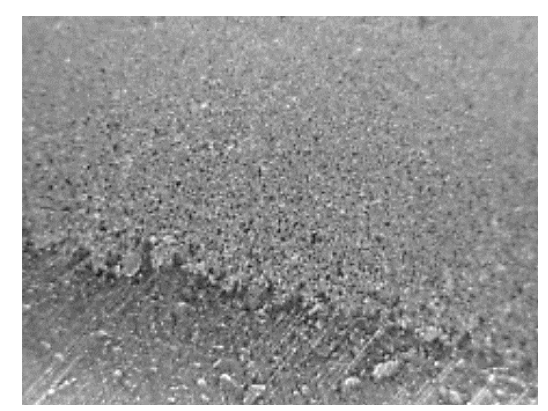

(b)

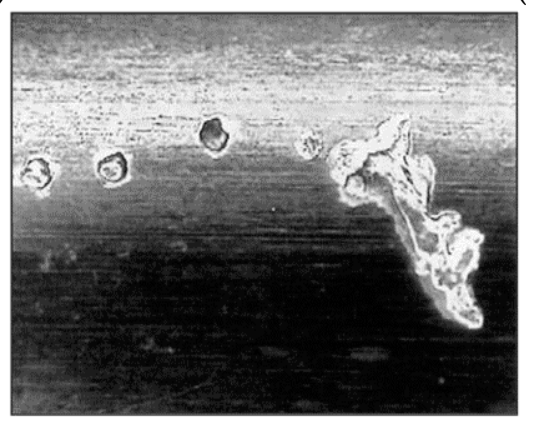

(c)

Figure 4. The visual appearance of shaft currents on the surfaces of the bearings: (a) fluting, (b) frosting, (c) pitting $[29,30]$.

\section{Diagnostic Possibilities}

Almost all advanced condition monitoring and fault diagnostics methods depend on signal processing techniques. Among a variety of signal processing techniques, the Fourier transform has been widely used for the conversion of a signal from the time domain to the frequency domain. Although the Fourier transform is a very strong tool for the analysis of a signal, it possesses several limitations. The algorithm, which can solve the complex Fourier formulas for a signal in a quicker way, is called the fast Fourier transform (FFT). The ideal FFT formula is designed for a signal of infinite length, as shown in Equation (1), which is practically not possible:

$$
f(t)=\sum_{n=-\infty}^{\infty} C_{n} e^{i n \omega t} \cong \sum_{n=1}^{N} C_{n} e^{i n \omega t}
$$

where;

$$
\begin{gathered}
\omega=2 \pi \frac{f}{f_{s}} \\
C_{n}=\frac{1}{2 \pi} \int_{-\infty}^{\infty} f(x) e^{-i n x} d x, n=0, \pm 1, \pm 2, \ldots \ldots
\end{gathered}
$$


where $C_{n}$ is the complex Fourier and $f(x)$ is the signal under investigation and $f s$ is the sampling frequency $(100 \mathrm{kHz})$.

The length of the signal can be reduced by truncating the signal to a finite length. This truncation can be done using various windowing functions such as rectangular, Hamming, Chebyshev, Hann, etc. These windows start leaking their energy in the frequency bins of the spectrum, which is called the spectral leakage. Moreover, if the signal is the same in all other similar intervals, it means that the signal is stationary and in the steady-state regime. Similarly, the discontinuities in the signal can be fatal for the frequency analysis using FFT.

The field of fault diagnostics is very broad containing a huge number of industrial and domestic applications. All applications are different in design, structure, working environment, and the types of signals which can be used for its condition monitoring. The signals can be broadly classified into two types, stationary and non-stationary. Although, the majority of applications work in a steady-state regime where the signals are supposed to be stationary and without discontinuities, in some applications, the transient analysis can give more concrete information about their health. In the transient interval, most of the signals are non-stationary, which makes their time-frequency analysis inevitable.

The FFT fails to do time-frequency analysis of a non-stationary signal while taking it as a single truncated piece. However, this problem can be solved by moving the window across the signal and doing the Fourier analysis of the signal in that particular window while considering the signal in the window as stationary. This approach is called a short-time Fourier transform (STFT). Although, this technique can give the time-frequency analysis of the signal that the spectrum resolution is the problem. This resolution problem is because of the inherited drawbacks of the FFT algorithms upon which STFT depends. If someone increases the length of the moving window, he can get good frequency resolution but poor time resolution. Similarly, by decreasing the length of the truncation window, the time resolution can be improved but frequency resolution will be poor. Therefore, there is a trade-off between time and frequency resolution of the spectrum according to Heisenberg's uncertainty principle.

These FFT-related problems can be avoided to a great extent by using the wavelet transform. Unlike STFT where the signal is divided into the small chunks and FFT is the performer for each, in wavelet transform, a window of known amplitude and frequency is swiped across the complete signal to check the location where it fits the most with the signal. This moving window is called the mother wavelet which is swiped across the signal $\mathrm{n}$ times with varying amplitude and frequency. It can give a much better resolution as compared to the corresponding STFT but at the cost of increased complexity. A comparison of the common diagnostic techniques is presented in Table 1.

Table 1. Comparison of diagnostic techniques [36].

\begin{tabular}{|c|c|c|}
\hline $\begin{array}{l}\text { Diagnostic } \\
\text { Technique }\end{array}$ & Benefits & Drawbacks \\
\hline \multirow{3}{*}{ FFT } & Small losses of information. & $\begin{array}{l}\text { Works only with stationary signals } \\
\text { Aliasing }\end{array}$ \\
\hline & & Bad resolution \\
\hline & Less computational power & Spectral leakage \\
\hline \multirow{4}{*}{ STFT } & & Bad time-frequency resolution, \\
\hline & Analysis of non-stationary signals & spectral leakage, \\
\hline & & $\begin{array}{c}\text { allasing } \\
\text { Compromise between time and frequency }\end{array}$ \\
\hline & $\begin{array}{l}\text { 3-D (time-trequency-amplitude) plots can be } \\
\text { more informative. }\end{array}$ & $\begin{array}{c}\text { More computational power is required as } \\
\text { compared to FFT }\end{array}$ \\
\hline \multirow{2}{*}{$\begin{array}{l}\text { Wavelet } \\
\text { transform }\end{array}$} & $\begin{array}{l}\text { Very precise technique, } \\
\text { Better time-frequency resolution }\end{array}$ & $\begin{array}{l}\text { More memory and computational power are } \\
\text { required as compared to STFT }\end{array}$ \\
\hline & $\begin{array}{l}\text { More efficient and flexible for analysis, analysis } \\
\text { of non-stationary signals. }\end{array}$ & Precision requires more iterations. \\
\hline Advanced & More efficient analysis & Sophisticated technology is required, \\
\hline techniques & More precise results & Requires a lot of computational power. \\
\hline
\end{tabular}


With the growing power of the computers and onboard processors, cloud computations, and the Industry 4.0 standards, the world is moving toward advanced predictive maintenance techniques. Unlike protective and reactive maintenance techniques, predictive maintenance techniques are becoming increasingly popular because of their positive financial impact. The advanced diagnostic techniques may include pattern recognition, machine learning, parameters estimation, neural networks, Fuzzy logic, and inverse problem theory, etc., [35,37-39]. However, all those techniques somehow depend on the fundamental signal processing techniques, described in Table 1.

\section{Experimental Setup and Methods}

In the framework of the given research, the typical bearing faults were inflicted on the bearings with the purpose of investigating the failure effect on the vibration spectrum of the motor. There were used identical ball bearings made from chrome steel with the same material standard. For the experiments, a three-phase BLDC intended for electric scooter application was used. All the measurements were performed at rated rotating speed $600 \mathrm{rpm}$. As the signal measuring tool, there were used three acceleration sensors $\pm 4 \mathrm{~g}$ type QG40N, which were screwed to the test bench. The sensitivity error of used acceleration sensors is $< \pm 1 \%$.

In the experiments, as shown in Figure 5, there were used three identical acceleration sensors, which were screwed into the test bench at different distances. Sensor 1 was mounted over the shaft of the motor, where the vibrations are supposed to be higher and more tangible on the vibration spectrum. Sensor 2 was placed beyond the shaft. Sensor 3 was mounted on the most distant edge from the motor. It was done in order to find an optimal place for the data acquisition. This paper focuses on the data taken from Sensor 1 which was placed over the shaft of the machine. Because of the proximity to the motor shaft, the vibrations in Sensor 1 are more tangible, which in turn provides more accurate results.

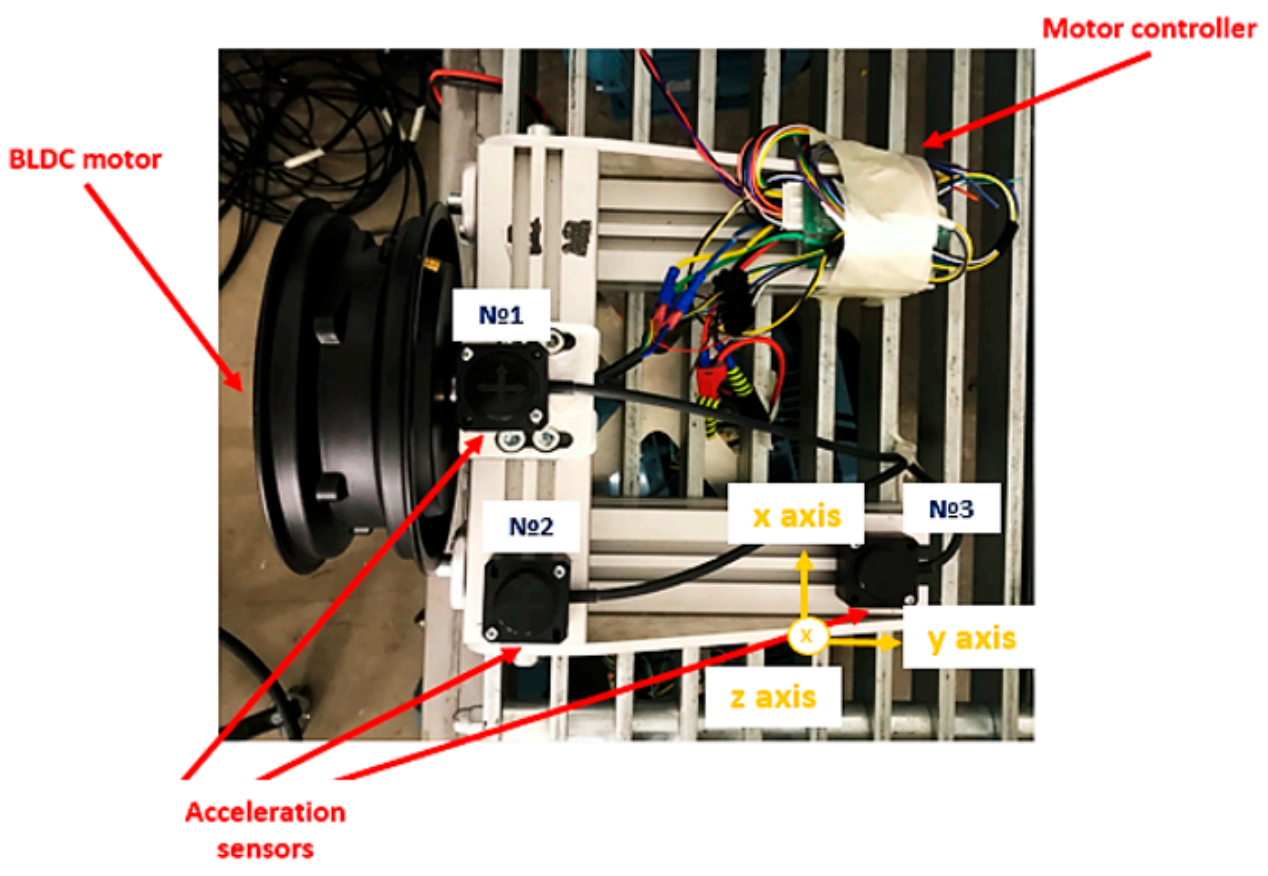

Figure 5. Placement of acceleration sensors on the test bench.

Data acquisition was performed at sampling rate $100 \mathrm{kHz}$ using Dewetron OXYGEN software. In the framework of the given experiment, only fast Fourier transform (FFT) is used to detect and compare the amplitude of the fundamental frequency component in case of healthy and faulty bearings. The FFT algorithms are well mature and are very easy to be implemented in Matlab. 
As the given motor is used in a certain application, specifically in electric scooter application, seven typical bearing failures, which can occur during the scooter operation, were chosen and inflicted on bearings, as shown in Figure 6. Eventually, eight bearings were tested.

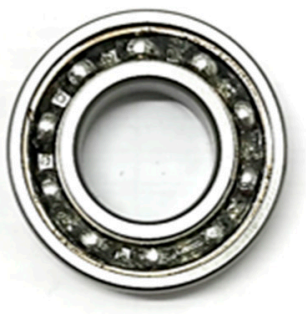

(a)

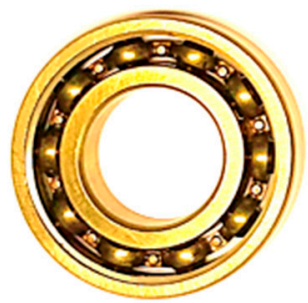

(e)

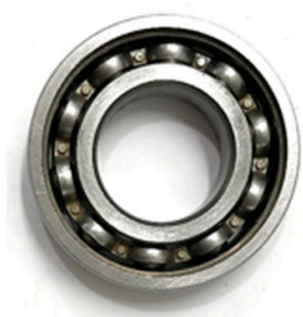

(b)

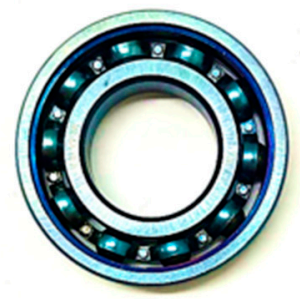

(f)

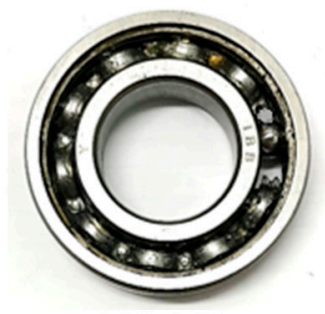

(c)

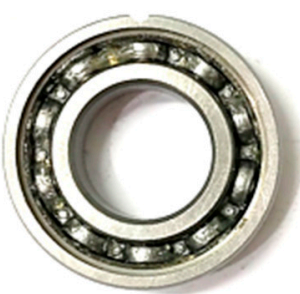

(g)

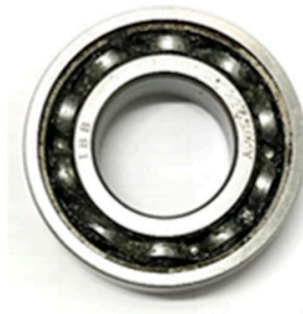

(d)

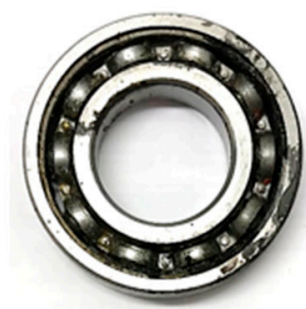

(h)

Figure 6. Tested bearings: (a) healthy bearing, (b) bearing without lubricant, (c) bearing with damaged separator, (d) contaminated bearing, (e) bearing tempered at $230{ }^{\circ} \mathrm{C}$, (f) bearing tempered at $330{ }^{\circ} \mathrm{C}$, (g) bearing with the cut outer raceway, (h) corroded bearing.

Faulty bearings present a specific vibration spectrum, which differs from the spectrum occurring in the case of a healthy bearing. In theory, it is possible to differentiate four fundamental frequencies (harmonics) in a loaded rolling bearing, which are used for diagnostics. Specific processes on different parts of the bearing cause these harmonics. In the literature, these processes (parameters) are designated as follows: rotation frequency on the outer raceway $\left(\mathrm{F}_{\mathrm{H}}\right)$, rotation frequency on the inner raceway $\left(\mathrm{F}_{\mathrm{B}}\right)$, operation of the bearing cage $\left(\mathrm{F}_{\mathrm{C}}\right)$, and rotation frequency of the bearing balls $\left(\mathrm{F}_{\mathrm{TK}}\right)$. The numerical values of the frequencies of these harmonics depend on the ratio of the geometric dimensions of the bearing elements, and, of course, are uniquely related to the rotation frequency of the rotor $\left(\mathrm{F}_{1}\right)$.

Practically, three most frequently encountered types of signals spectra, which correspond to various stages of defect development can be identified. On the first stages of defect development, as shown in Figure $7 \mathrm{a}$, a presentable harmonic $\mathrm{F}_{\mathrm{H}}$ appears on the FFT spectrum. The presence of the frequency peak on the spectrum allows to suppose and identify explicitly an existence of the defective element.

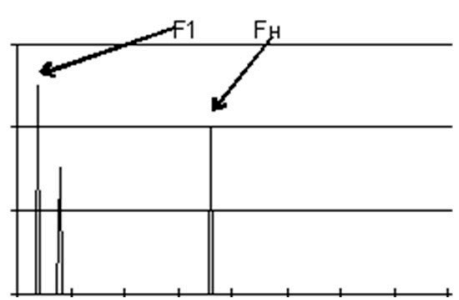

(a)

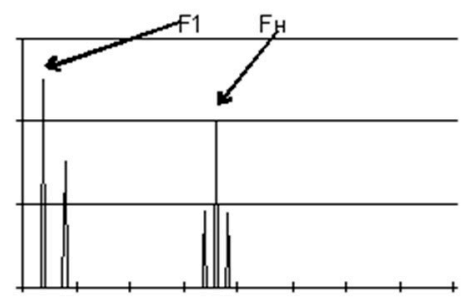

(b)

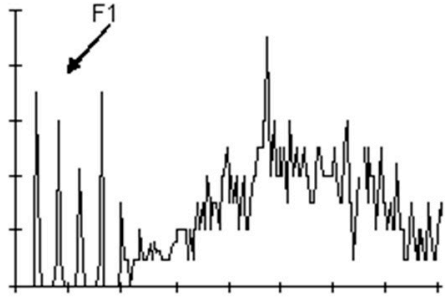

(c)

Figure 7. Stages of damage development: (a) early fault stage; (b) progressive fault stage; (c) final fault stage [40]. 
As the defect develops, the first pair of side harmonics on the left and right side near the main frequency peak, as shown in Figure $7 \mathrm{~b}$, can be observed on the spectrum. With further degradation, other frequency pairs appear near the main frequency peak. In the given research, a good example of this phenomenon was observed in relation to contaminated bearing. The reason for this phenomenon is that the failed rolling body shifts so much that the adjacent rolling bodies already bear the main load to support the shaft of the mechanism [40].

At this stage, the bearing fulfills its intended functions. However, because of the added stresses, further operation of the bearing leads to definite breakdown of the device. In the last stages, the failure develops to such an extent, that the bearing degrades and does not fulfill its functions. This stage can be identified by appearing of additional harmonics, which have a random character, as shown in Figure 7c. This occurrence was not detected in this experiment.

As discussed, for data analysis different diagnostic techniques can be used. In the given research, as the signal is stationary and the motor rotates with constant speed, FFT was chosen to analyze the results. For the clearer data presentation, signals FFT spectra were also studied and presented on the logarithmic scale.

\section{Result Analysis and Discussion}

Figure 8 presents the vibration signals of the healthy bearing. As it can be seen, the most noticeable vibration signal (y-axis) comes from sensor 1, which was placed above the motor shaft.
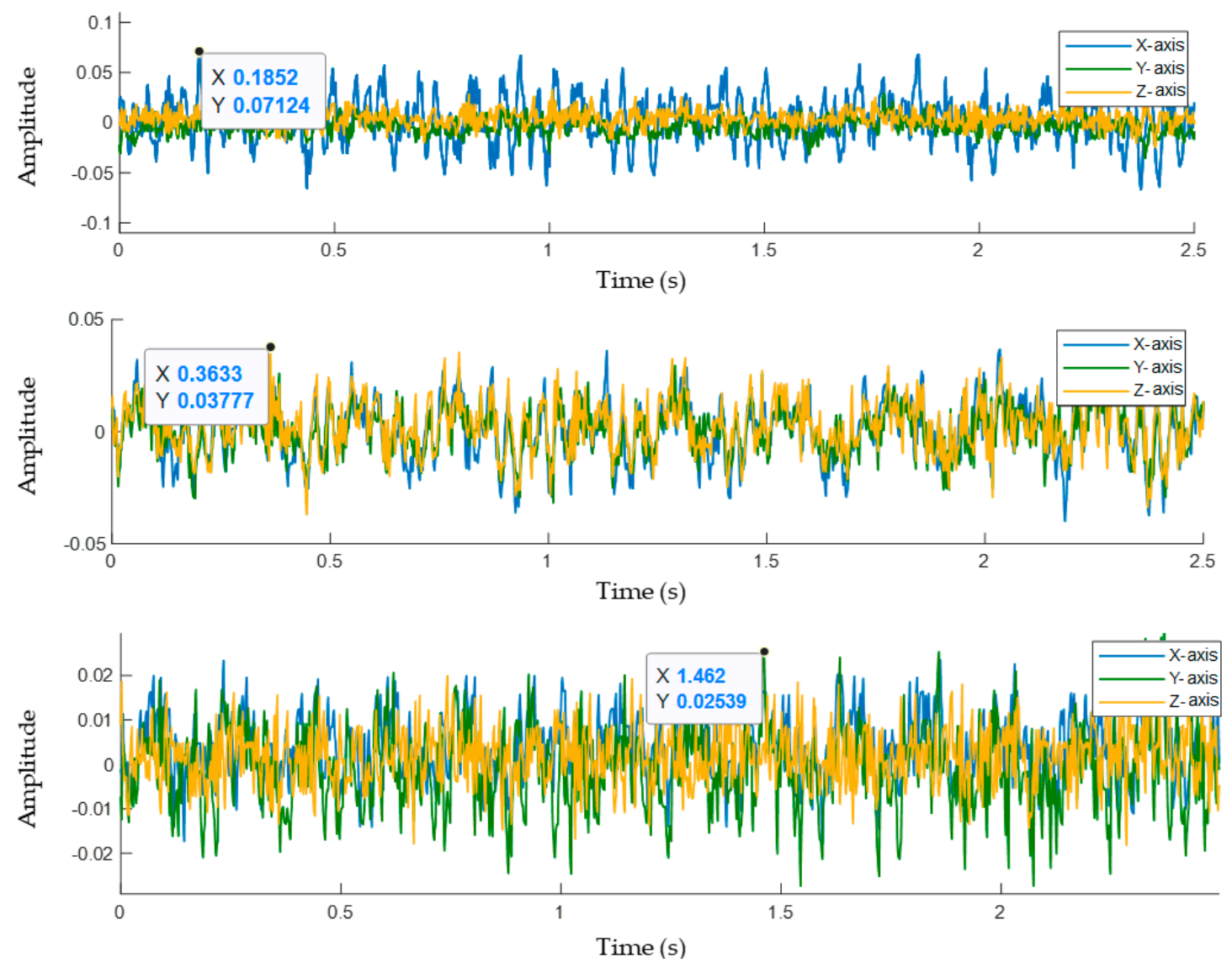

Figure 8. Vibration signals of healthy bearing: (top) signal taken from sensor 1, (middle) signal taken from sensor 2, (bottom) signal taken from sensor 3. 
By moving away from the shaft, the vibrations decrease. Therefore, the signal taken from sensor 1 would be more informative in the further result analysis. Mainly, the vibrations occur in $x$-axis, while the signal in $y$ - and z-axes does not change much.

Every system has a bandwidth of vibrational frequencies, which depends upon its natural frequency bandwidth and a variety of parameters, such as ambient factors, foundation of the motor, etc. In the given research, the most prominent frequencies appear in a frequency range of about $15 \mathrm{~Hz}-35 \mathrm{~Hz}$. In the framework of given research, the amplitude of the most powerful vibrational frequency component of faulty bearing was compared with the one obtained from the healthy bearing.

The FFT spectrum of healthy bearing is shown in Figure 9. The window length in this case, as well as in the following graphs, is 31,0195 samples. In the case of healthy bearing, the acceleration amplitude of the fundamental harmonic reaches the value of $0.00251 \mathrm{~m} / \mathrm{s}^{2}$ at the frequency $25.33 \mathrm{~Hz}$. Comparing it with the spectra of the faulty bearings, which are shown and discussed below, it can be seen that the acceleration amplitudes of the faulty bearings are much higher.

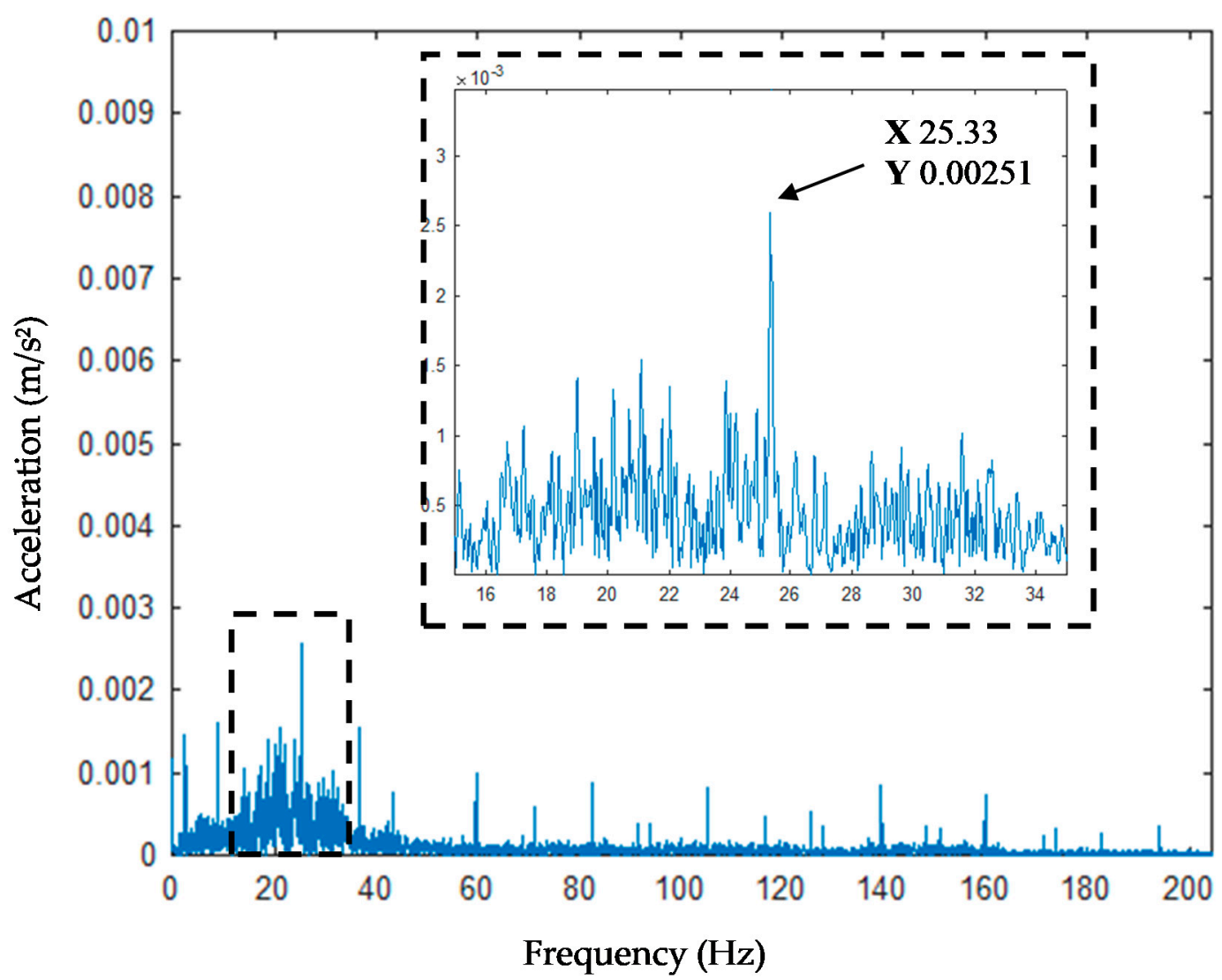

Figure 9. Fast Fourier transform (FFT) spectra of healthy bearing in the range of $0-200 \mathrm{~Hz}$.

For better representation of the signals of faulty bearings, all of the inflicted damages were grouped and presented separately as the FFT spectra. The first group of the faults (contaminated and corroded bearings) can be referred to as damages caused by ambient factors. The most noticeable acceleration amplitude was observed in the case of contaminated bearing, which is $0.0102 \mathrm{~m} / \mathrm{s}^{2}$. Another fault, where FFT spectrum differs compared to healthy bearing, is corrosion. From Figure 10, a wide spectrum of harmonics in the range of $0-40 \mathrm{~Hz}$ and frequency peaks in the range of $120-170 \mathrm{~Hz}$ can be observed, which in turn indicates the presence of a fault in the bearing. 


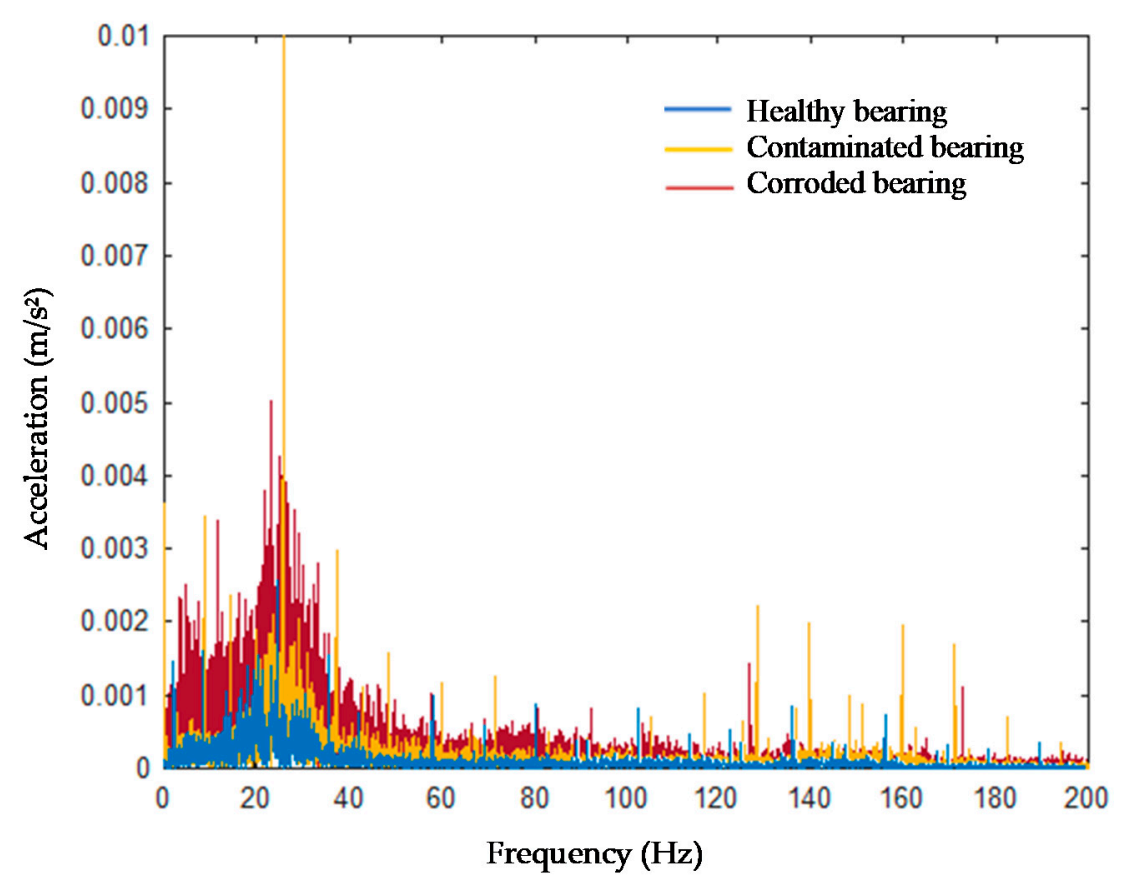

(a)

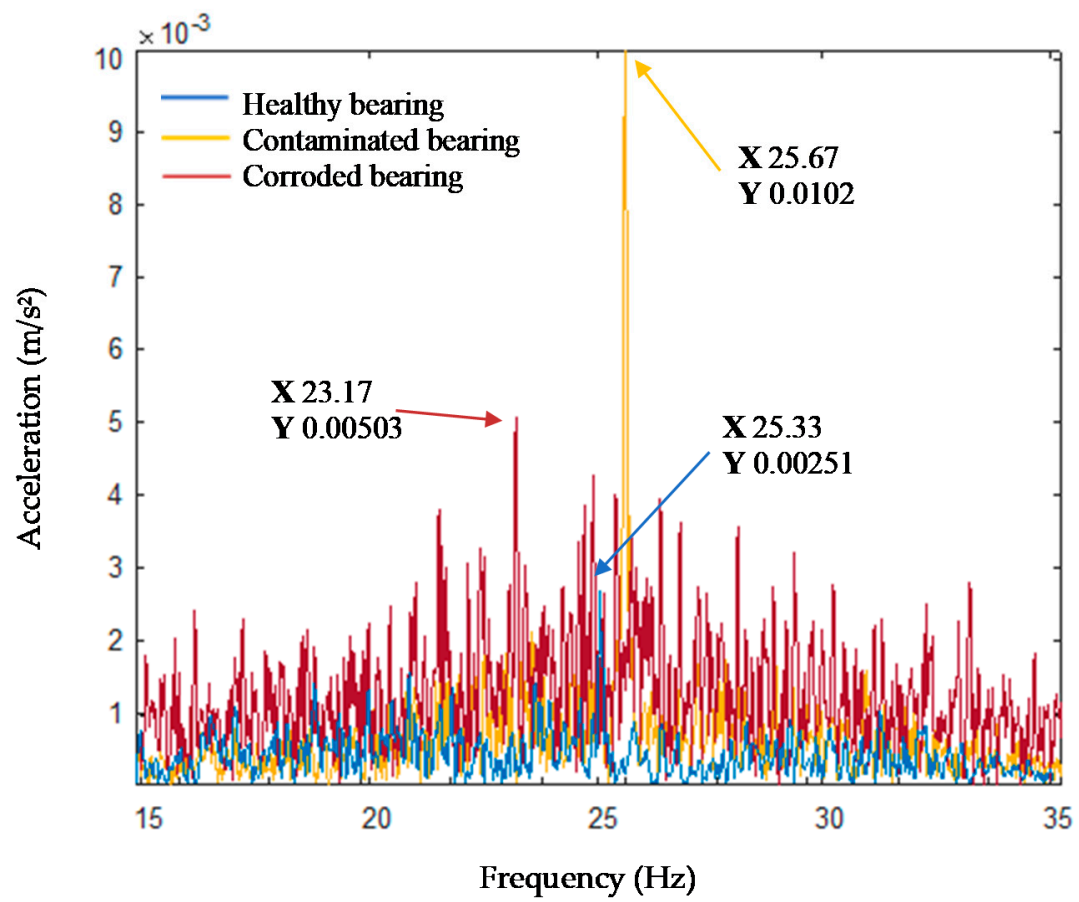

(b)

Figure 10. FFT spectra of contaminated and corroded bearings in comparison with healthy bearing: (a) FFT spectrum, (b) FFT spectrum in the range of 15-35 Hz.

In the following experiment, bearings tempered at different temperatures were investigated. Comparing these spectra with each other, there is no significant difference. As seen from Figure 11, in both cases the side harmonics appear in the spectrum on the left and right side of the main frequency peak. In addition, a frequency spectrum in the range of $120-170 \mathrm{~Hz}$ was observed. All these aspects notify of the presence of damage and mechanical weakening in the bearing. 


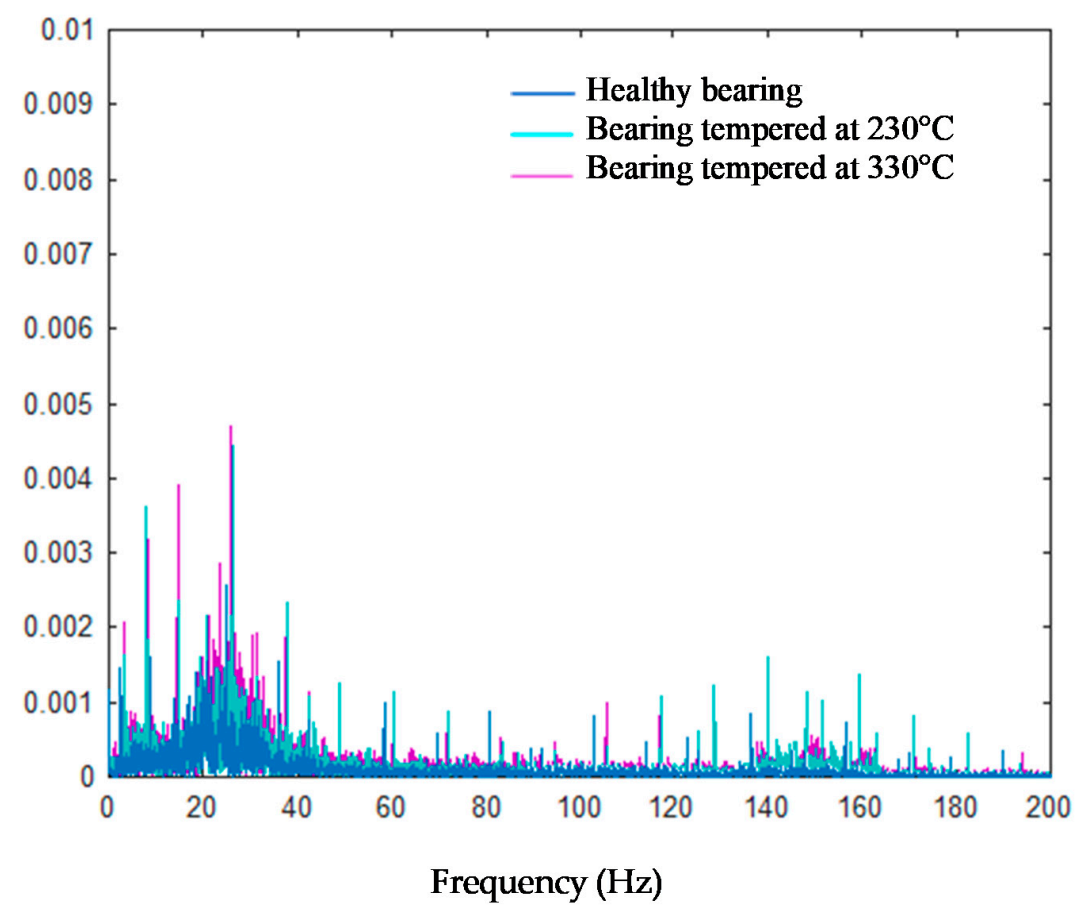

(a)

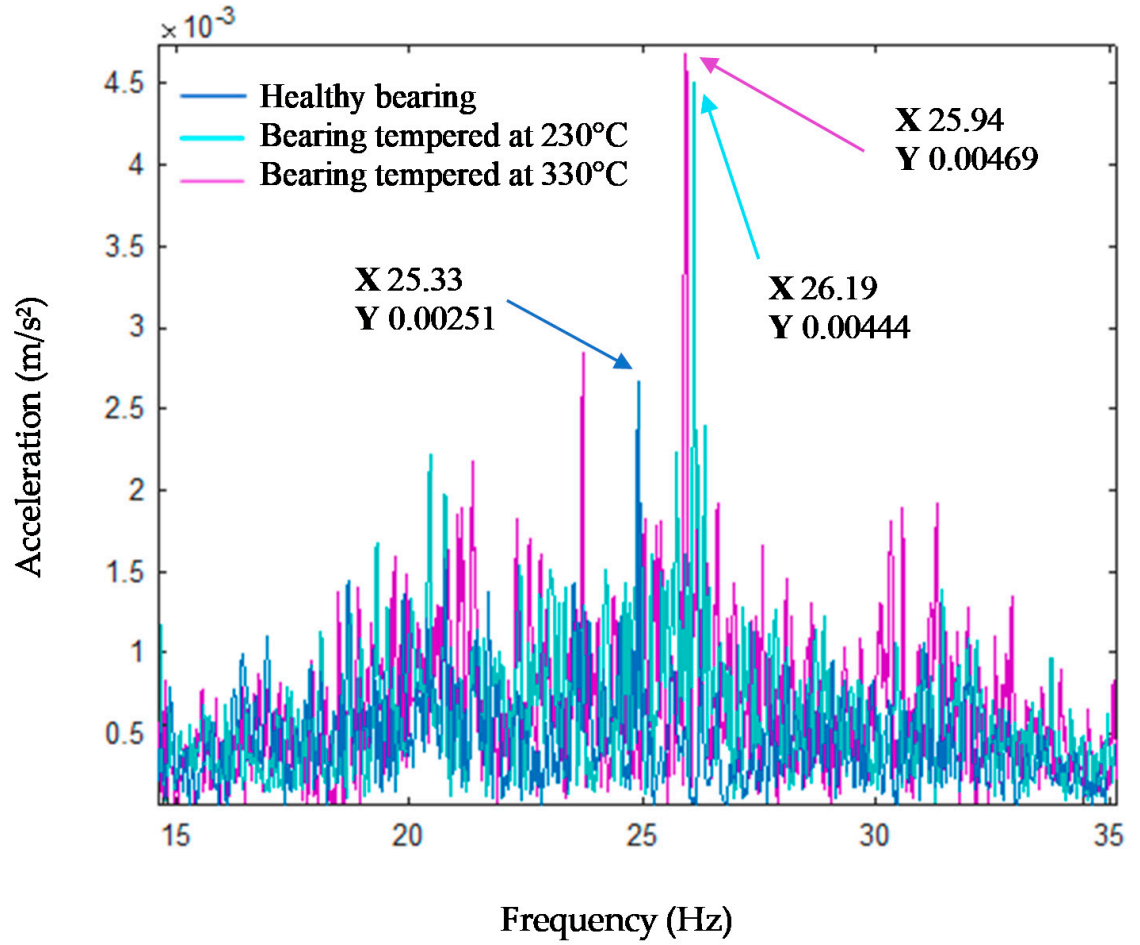

(b)

Figure 11. FFT spectra of tempered bearings in comparison with healthy bearing: (a) FFT spectrum, (b) FFT spectrum in the range of $15-35 \mathrm{~Hz}$.

In the case of the last fault group (bearing with cut outer raceway, bearing with damaged separator, and bearing with removed lubricant), the faults spectra appear similarly to the ones of tempered bearings, as seen from Figure 12. Presentable frequency peaks can be observed in each of the cases. Similarly to the faults discussed previously, frequency spectra in the range of $120-170 \mathrm{~Hz}$ can be also observed. 


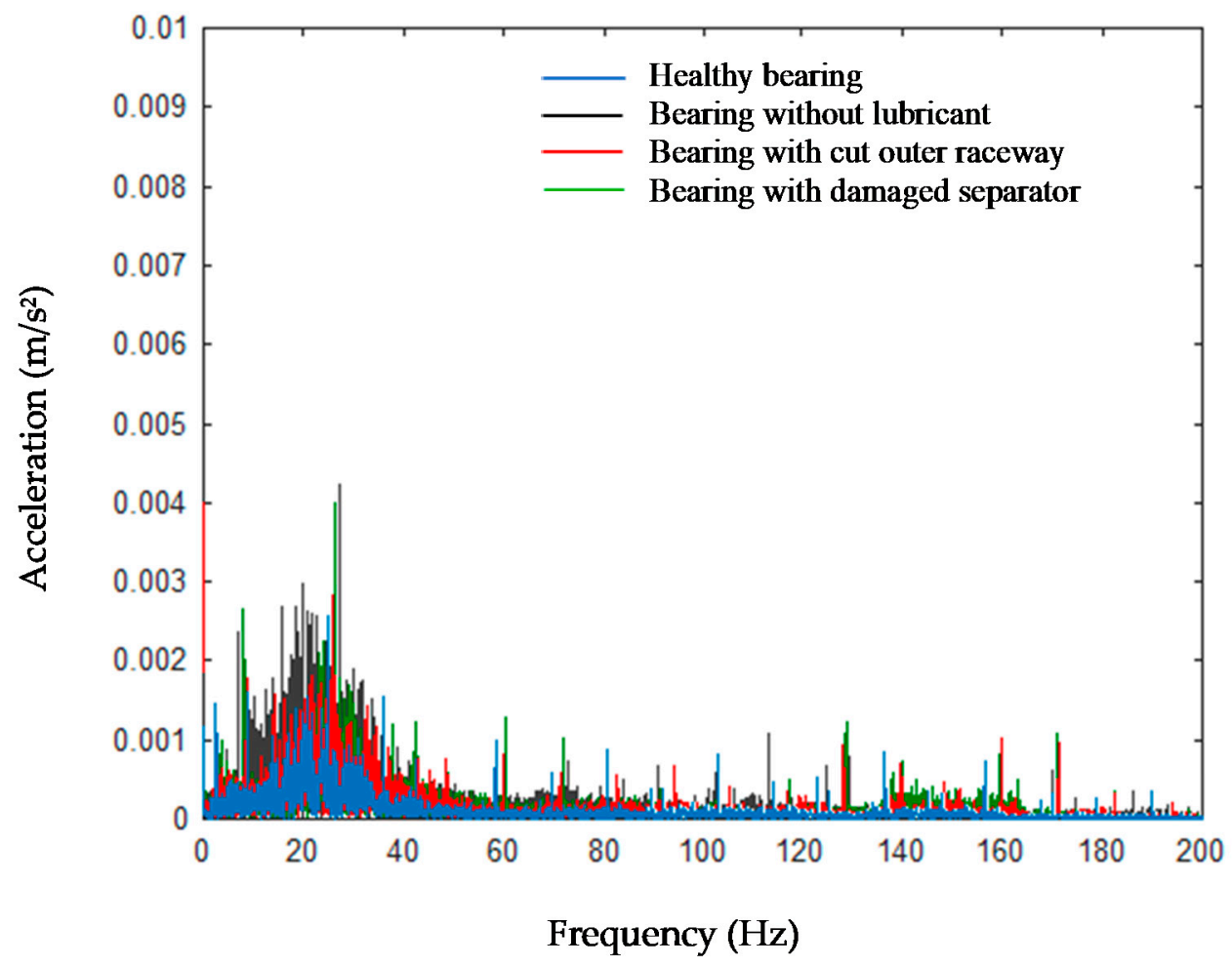

(a)

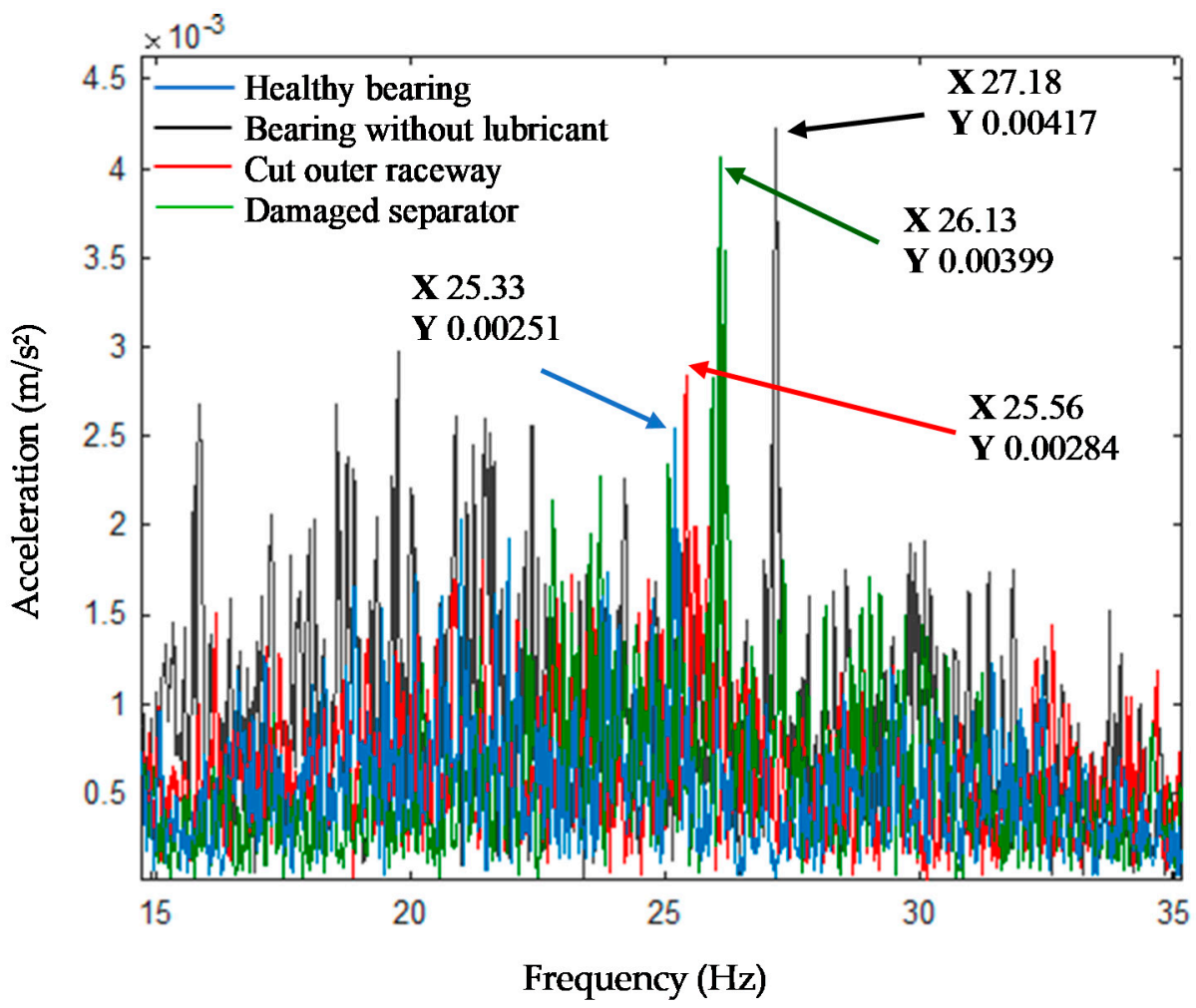

(b)

Figure 12. FFT spectra of faulty bearings in comparison with healthy bearing: (a) FFT spectrum, (b) FFT spectrum in the range of $15-35 \mathrm{~Hz}$. 
A comparison analysis of the results is shown in Table 2. Out of the several harmonics the most powerful component (fundamental) is chosen as the benchmark signal in the healthy case. The difference in the amplitude of that component defines the severity of the fault.

Table 2. Comparing table of the results.

\begin{tabular}{cccc}
\hline Bearing & Faulty Frequency $\mathbf{( H z )}$ & $\begin{array}{c}\text { Acceleration Amplitude } \\
\left(\mathbf{m} / \mathbf{s}^{\mathbf{2}}\right)\end{array}$ & $\begin{array}{c}\text { Difference in Acceleration } \\
\text { Compared to Heathy Bearing } \\
\left(\mathbf{m} / \mathbf{s}^{\mathbf{2}}\right)\end{array}$ \\
\hline $\begin{array}{c}\text { Healthy bearing } \\
\text { Contaminated bearing }\end{array}$ & 25.33 & 0.00251 & - \\
Corroded bearing & 25.67 & 0.0102 & 0.00769 \\
Bearing tempered at $230^{\circ} \mathrm{C}$ & 23.17 & 0.00503 & 0.00252 \\
Bearing tempered at $330^{\circ} \mathrm{C}$ & 26.19 & 0.00444 & 0.00193 \\
Without lubricant & 25.94 & 0.00469 & 0.00218 \\
$\quad$ Cut bearing & 25.56 & 0.00284 & 0.00033 \\
Damaged separator & 26.13 & 0.00399 & 0.00148 \\
\hline
\end{tabular}

As presented, the most noticeable difference in acceleration compared to healthy bearing was found in the case of contaminated bearing, which is $0.00769 \mathrm{~m} / \mathrm{s}^{2}$. The smallest difference in acceleration $\left(0.00148 \mathrm{~m} / \mathrm{s}^{2}\right)$ occurred in the case of bearing, in which the outer raceway was cut. In the light of the above results, it is evident that with the inclusion of fault the fundamental vibration component goes stronger. The more developed the damage is, the stronger is the vibration component. The amplitude of this component can be considered as fault indicator. Moreover, each fault gives its specific frequency pattern. Therefore, based on the spectrum, it is possible to detect and segregate the fault type.

\section{Conclusions}

Over the past years, BLDC motors have gained wide attention in different domestic and industrial branches because of their characteristics. Because of popularity gain, the unexpected faults of such motors can be fatal and lead to negative consequences. In reference to motor failures, many studies have been done with regard to stator or rotor faults. Although the topic of bearing related faults has not been particularly revealed and discussed in the literature. Nevertheless, the bearing is the basic component of the electrical machine and unforeseen faults are unfavorable.

This paper proposes a study of bearing faults and their diagnostics possibilities. In the framework of the given research, the most common bearing failures were discussed and the reasons for these failures were explained. In this experiment, seven typical bearing faults were inflicted on the healthy bearing. In the experiments, BLDC motor intended for electric scooter application was used. Therefore, the most spread faults that can occur during the electric scooter exploitation were applied to the bearings. This study presents a possible method for bearing fault detection in BLDC motor using acceleration sensors.

Different bearing faults were compared and analyzed. The experimental results in Section 3 address that each damage gives a specific vibration spectrum. According to the spectrum, the type and the development stage of the damage can be detected. The amplitude of the fundamental vibration frequency component can be used for defining a threshold level. It also can be a reliable indicator of fault rather than the detection of certain harmonics from a wide range of frequencies. The integration of other sophisticated diagnostic techniques into research and improvement of the given analysis method will be considered as future work. 
Author Contributions: Conceptualization, K.K., T.V., and B.A.; methodology, A.K. and A.R.; validation, K.K., T.V., and B.A.; data curation, A.K.; writing-original draft preparation, K.K.; writing-review and editing, T.V. and D.V.L.; visualization, A.R.; supervision, A.B. All authors have read and agreed to the published version of the manuscript.

Funding: This research has been funded by the Estonian Research Council under grant PSG453 “Digital twin for propulsion drive of autonomous electric vehicle." This research has been supported by the Government of the Russian Federation, Grant 08-08.

Conflicts of Interest: The authors declare no conflict of interest.

\section{References}

1. Ismagilov, F.R.; Vavilov, V.Y.; Bekuzin, V.I.; Chirkov, V.S. Design analysis of submersible brushless dc motors for the oil and gas industry. In Proceedings of the 2019 International Conference on Electrotechnical Complexes and Systems (ICOECS), Ufa, Russia, 21-25 October 2019; pp. 1-5. [CrossRef]

2. Kumar, R.; Singh, B. BLDC Motor-Driven Solar PV Array-Fed Water Pumping System Employing Zeta Converter. IEEE Trans. Ind. Appl. 2016, 52, 2315-2322. [CrossRef]

3. Kumar, R.; Singh, B. Solar PV-battery based hybrid water pumping system using BLDC motor drive. In Proceedings of the 2016 IEEE 1st International Conference on Power Electronics, Intelligent Control and Energy Systems (ICPEICES), Delhi, India, 4-6 July 2016. [CrossRef]

4. Chen, Y.T.; Chiu, C.L.; Jhang, Y.R.; Tang, Z.H.; Liang, R.H. A driver for the single-phase brushless DC fan motor with hybrid winding structure. IEEE Trans. Ind. Electron. 2013, 60, 4369-4375. [CrossRef]

5. Fan, Y.; Chau, K.T.; Niu, S. Development of a new brushless doubly fed doubly salient machine for wind power generation. IEEE Trans. Magn. 2006, 42, 3455-3457. [CrossRef]

6. Wu, B.; Zhuo, F.; Long, F.; Gu, W.; Qing, Y.; Liu, Y. A management strategy for solar panel battery super capacitor hybrid energy system in solar car. In Proceedings of the 8th International Conference on Power Electronics-ECCE Asia, Jeju, Korea, 30 May-3 June 2011; Volume 2, pp. 1682-1687. [CrossRef]

7. Liu, C.; Chau, K.T.; Zhang, X. An efficient wind-photovoltaic hybrid generation system using doubly excited permanent-magnet brushless machine. IEEE Trans. Ind. Electron. 2010, 57, 831-839. [CrossRef]

8. Yildirim, M.; Polat, M.; Kurum, H. A survey on comparison of electric motor types and drives used for electric vehicles. In Proceedings of the 2014 16th International Power Electronics and Motion Control Conference and Exposition, Antalya, Turkey, 21-24 September 2014; pp. 218-223. [CrossRef]

9. Moon, J.J.; Im, W.S.; Kim, J.M. Novel phase advance method of BLDC motors for wide range speed operations. In Proceedings of the 2013 Twenty-Eighth Annual IEEE Applied Power Electronics Conference and Exposition (APEC), Long Beach, CA, USA, 17-21 March 2013; pp. 2343-2348. [CrossRef]

10. Cui, C.; Liu, G.; Wang, K. A novel drive method for high-speed brushless dc motor operating in a wide range. IEEE Trans. Power Electron. 2015, 30, 4998-5008. [CrossRef]

11. Haines, G.; Ertugrul, N. Wide Speed Range Sensorless Operation of Brushless Permanent-Magnet Motor Using Flux Linkage Increment. IEEE Trans. Ind. Electron. 2016, 63, 4052-4060. [CrossRef]

12. Shenoy, K.L. Design Topology and Electromagnetic Field Analysis of Permanent Magnet Brushless DC Motor for Electric Scooter Application. In Proceedings of the 2016 International Conference on Electrical, Electronics, and Optimization Techniques (ICEEOT), Chennai, India, 3-5 March 2016; pp. 1541-1545. [CrossRef]

13. Rajagopalan, S.; Restrepo, J.A.; Aller, J.M.; Habetler, T.G.; Harley, R.G. Selecting time-frequency representations for detecting rotor faults in BLDC motors operating under rapidly varying operating conditions. In Proceedings of the 31st Annual Conference of IEEE Industrial Electronics Society, IECON 2005, Raleigh, NC, USA, 6-10 November 2005; pp. 2585-2590. [CrossRef]

14. Lee, S.T.; Hur, J. Detection technique for stator inter-turn faults in BLDC motors based on third-harmonic components of line currents. IEEE Trans. Ind. Appl. 2017, 53, 143-150. [CrossRef]

15. Dong, L.; Jatskevich, J.; Huang, Y.; Chapariha, M.; Liu, J. Fault diagnosis and signal reconstruction of hall sensors in brushless permanent magnet motor drives. IEEE Trans. Energy Convers. 2016, 31, 118-131. [CrossRef]

16. Skora, M.; Ewert, P.; Kowalski, C.T. Selected rolling bearing fault diagnostic methods in wheel embedded permanent magnet brushless direct current motors. Energies 2019, 12, 4212. [CrossRef] 
17. Muślewski, Ł.; Pająk, M.; Grządziela, A.; Musiał, J. Analysis of vibration time histories in the time domain for propulsion systems of minesweepers. J. VibroEng. 2015, 17, 1309-1316.

18. Pająk, M. Identification of the operating parameters of a complex technical system important from the operational potential point of view. J. Syst. Control Eng. 2017, 232, 62-78. [CrossRef]

19. Asad, B.; Vaimann, T.; Belahcen, A.; Kallaste, A.; Rassõlkin, A.; Iqbal, M.N. Broken rotor bar fault detection of the grid and inverter-fed induction motor by effective attenuation of the fundamental component. IET Electr. Power Appl. 2019, 13, 2005-2014. [CrossRef]

20. Asad, B.; Vaimann, T.; Belahcen, A.; Kallaste, A.; Rassolkin, A. Rotor Fault Diagnostic of Inverter Fed Induction Motor Using Frequency Analysis. In Proceedings of the 2019 IEEE 12th International Symposium on Diagnostics for Electrical Machines, Power Electronics and Drives (SDEMPED), Toulouse, France, 27-30 August 2019; pp. 127-133. [CrossRef]

21. Asad, B.; Vaimann, T.; Kallaste, A.; Rassõlkin, A.; Belahcen, A.; Iqbal, M.N. Improving Legibility of Motor Current Spectrum for Broken Rotor Bars Fault Diagnostics. Electr. Control Commun. Eng. 2019, 15, 1-8. [CrossRef]

22. Asad, B.; Vaimann, T.; Belahcen, A.; Kallaste, A.; Rassolkin, A.; Iqbal, M.N. Modified Winding Function-based Model of Squirrel Cage Induction Motor for Fault Diagnostics. IET Electr. Power Appl. 2020, 14, 1722-1734. [CrossRef]

23. Frosini, L.; Zanazzo, S.; Albini, A. A wavelet-based technique to detect stator faults in inverter-fed induction motors. In Proceedings of the 2016 XXII International Conference on Electrical Machines (ICEM), Lausanne, Switzerland, 4-7 September 2016; pp. 2917-2923. [CrossRef]

24. Farajzadeh-Zanjani, M.; Razavi-Far, R.; Saif, M.; Rueda, L. Efficient feature extraction of vibration signals for diagnosing bearing defects in induction motors. In Proceedings of the 2016 International Joint Conference on Neural Networks (IJCNN), Vancouver, BC, Canada, 24-29 July 2016; pp. 4504-4511. [CrossRef]

25. Rosero, J.A.; Cusido, J.; Garcia, A.; Ortega, J.A.; Romeral, L. Broken bearings and eccentricity fault detection for a permanent magnet synchronous motor. In Proceedings of the IECON 2006-32nd Annual Conference on IEEE Industrial Electronics, Paris, France, 6-10 November 2006; pp. 964-969. [CrossRef]

26. Dasgupta, A.; Pecht, M. Material Failure Mechanisms and Damage Models. IEEE Trans. Reliab. 1991, 40, 531-536. [CrossRef]

27. SKF. Manual of SKF Bearings Maintenance (in Estonian); Teriteka Ldt.: Budapest, Hungary, 1998.

28. Hodowanec, M.M. Evaluation of antifriction bearing lubrication methods on motor lifecycle cost. IEEE Trans. Ind. Appl. 1999, 35, 12471251. [CrossRef]

29. Sores, P.; Orosz, T.; Vajda, I. Lifetime Cost Sensitivity Assessment on Optimal Core-form Power Transformer Design. CRF 2014, 11, 2.

30. Rassõlkin, A.; Belahcen, A.; Kallaste, A.; Vaimann, T.; Dmitry, V.; Lukichev, S.O.; Heidari, H.; Asad, B.; Acedo, J.P. Life cycle analysis of electrical motor drive system based on electrical machine type. Proc. Est. Acad. Sci. 2020, 69, 162-177. [CrossRef]

31. Nabhan, A.; Ghazaly, N.M.; Samy, A. Bearing Fault Detection Techniques-A Review. Turk. J. Eng. Sci. Technol. 2015, 3, 1-18.

32. NSK. Handling Instruction for Bearings; NSK: Tokyo, Japan, 2004.

33. SKF. Bearing Damage and Failure Analysis; SKF: Gothenburg, Sweden, 2017.

34. Kudelina, K.; Asad, B.; Vaimann, T.; Rassolkin, A.; Kallaste, A. Effect of Bearing Faults on Vibration Spectrum of BLDC Motor. In Proceedings of the 2020 IEEE Open Conference of Electrical, Electronic and Information Sciences (eStream), Vilnius, Lithuania, 30 April 2020; pp. 1-6. [CrossRef]

35. Bishop, T. Dealing with Shaft and Bearing Currents; EASA, Eletrical Apparatus Service Association: St. Louis, MO, USA, 2017.

36. Qi, Z.; Tian, Y.; Shi, Y. Robust twin support vector machine for pattern classification. Pattern Recognit. 2013, 46, 305-316. [CrossRef]

37. Chatterton, S.; Pennacchi, P.; Vania, A. Electrical pitting of tilting-pad thrust bearings: Modelling and experimental evidence. Tribol. Int. 2016, 103, 475-786. [CrossRef]

38. Kudelina, K.; Asad, B.; Vaimann, T.; Rassõlkin, A.; Kallaste, A.; Lukichev, D.V. Main Faults and Diagnostic Possibilities of BLDC Motors. In Proceedings of the 2020 27th International Workshop on Electric Drives: MPEI Department of Electric Drives 90th Anniversary (IWED), Moscow, Russia, 27-30 January 2020. 
39. Jnifene, A.; Andrews, W. Experimental study on active vibration control of a single-link flexible manipulator using tools of fuzzy logic and neural networks. IEEE Trans. Instrum. Meas. 2005, 54, 1200-1208. [CrossRef]

40. Rusov, V.A. Diagnostics of Defects in Rotating Equipment by Vibration Signals (in Russian); Vibro-Center: Perm, Russia, 2012. 